ojs.uv.es/index.php/qdfed

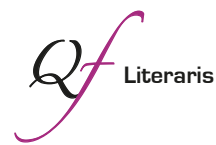

\title{
China y el Lejano Oriente en el relato de Benjamín de Tudela (siglo XII). Realidades y fantasías
}

\section{China and the Far East in Benjamín de Tudela's story (12th century). Realities and fantasies}

\author{
Alexandra Magdalena Mironesko ${ }^{\mathrm{a}}$ \& José Ramón Magdalena Nom de Déu ${ }^{\mathrm{b}}$ \\ a Universidad de Granada. magmir@ugr.es \\ b Universidad de Barcelona. magdalena@ub.edu \\ Recibido: 07/04/2018. Aceptado: 16/10/2018
}

Resumen: El texto hebreo del relato de los viajes e itinerarios del rabino Benjamín de Tudela (siglo XII, circa 1165-1173) contiene interesantes y curiosos datos étnicos, geográficos, económicos y míticos relacionados con remotas latitudes orientales: las tradicionales rutas comerciales centroasiáticas, la India, Malabar, Tíbet y la China, entre otros parajes. Informaciones reales o fantásticas que acaso debió recoger y anotar el judío tudelano durante su larga estancia en Bagdad, o fruto de posteriores interpolaciones y añadidos a cargo de los copistas.

Palabras clave: China; India; Oriente; mitos; viajes.

\begin{abstract}
The Hebrew text of the journey of the rabbi Benjamin mi-Tudela (circa 1165-1173) contains interesting, curious and fantastic data concerning ethnic, geographic, economic and mythic aspects related to remote oriental places such as India, Malabar, Tibet and China. This information probably arrived to the Jewish traveller when he stayed in Bagdad or Basra, or included and interpoled later in the manuscripts by the scribes and compilators.
\end{abstract}

Keywords: China; India; Orient; Myths; travelogue.

\) Magdalena Mironesko, Alexandra \& Magdalena Nom de Déu, José Ramón. 2018. "China y el Lejano Oriente en el relato de Benjamín de Tudela (siglo XII). Realidades y fantasías”. Quaderns de Filologia: Estudis Literaris XXIII: 143-156. doi: $10.7203 /$ qdfed.23.13467 

El documento más antiguo que ofrece la primera información sobre una posible llegada de dos viajeros musulmanes a diversos puertos del océano Pacífico es el manuscrito árabe del siglo IX titulado Aḥbar as-Ṣin wa'l-Hind (Noticias de la China y de la India) (Israeli, 2000: 313-321). No sería de extrañar que, poco después, judíos residentes en el nuevo y extenso ámbito islámico de Asia Central entrasen en contacto con China como mercaderes internacionales. Otras informaciones, también del siglo IX, dan cuenta de ciertas compañías comerciales de judíos, los radaniyya o radanitas - voz de origen persa que significa 'conocedores de los caminos'- dedicados al tráfico de esclavos, eunucos, pieles lujosas y espadas desde la Europa occidental a China, e importadores de almizcle, alcanfor y otras preciadas especias de aquellas lejanas latitudes. A finales del siglo IX el polígrafo persa 'Abul Qasim 'Ubaid-Allah ibn Hordadbihi (circa 820-912), nombrado por el califa Al-Mu'tamid jefe de la administración de los correos, la inteligencia y el espionaje de la provincia de Gibal (noroeste de Irán, actualmente Iraq), escribió en árabe su famoso Kitab al-masalik wa-al-mamalik (Libro de las Rutas y de los Reinos), donde menciona a estos judíos radanitas:

Éste es el camino de los comerciantes judíos llamados radanitas... viajan de Occidente a Oriente y regresan tanto por vía marítima como por vía continental... Embarcan en el país de los francos [Europa cristiana] para dirigirse a Faram y desde allí cargan sus mercancías sobre camellos y toman la vía terrestre hacia Kulsum [Suez], trayecto que dura cinco días. Desde Kulsum siguen la ruta marítima a través del Mar Rojo hacia Gidda [Arabia] y luego prosiguen hasta Sind, India y China (Gil, 1976: 299-328).

Otra ruta que seguían los radanitas atravesaba territorios de Mesopotamia, pasando por Bagdad hasta el puerto de Basra, desde donde embarcaban hacia los puertos comerciales de India y China. También viajaban por otras rutas terrestres alternativas, desde territorios cristianos occidentales (reinos hispánicos, Francia, Bizancio) y a través de complicados y azarosos viajes por ámbitos eurasiáticos alcanzaban sus lejanos objetivos.

En China entraban en contacto con sus correligionarios, allí establecidos desde muy antiguo, acaso ya en tiempos de la dinastía Han (漢) o incluso varios siglos antes. En Khotan (和田市), antiguo Turkestán chino, se halló una carta comercial del año 718 y un texto litúrgico 
hebreo. Para el año 878-879 tenemos noticias de judíos establecidos en la importante ciudad portuaria de Cantón (广州), asentados entre musulmanes, y en los siglos X-XI un millar de judíos, con mujeres y niños, fueron invitados a establecerse en Kaifeng(开封市) y acabaron mestizándose con la población local, si bien mantuvieron la religión judía (Díaz Esteban, 2009: 39). La comunidad de Kaifeng poseía un oratorio o sinagoga (清真寺) desde 1163, construida durante la dinastía Song (宋朝, 960-1279) y sus fieles eran conocidos por sus vecinos no judíos chinos como “miembros del Tiaojinjiao" (挑筋教), lo que viene a significar algo así como los de "la religión que quita el tendón", en alusión a la práctica de retirar el tendón isquiático de las patas de las reses sacrificadas según el ritual rabínico (Raiskin, 2006: 60-85).

Sirvan acaso estas notas introductorias documentando los antiguos y continuos contactos y presencia de musulmanes y judíos en la China y el Lejano Oriente, con el objeto de situar y enmarcar los escasos, difusos y controvertidos datos que sobre tan lejanos países se contienen en el texto hebreo de Benjamín de Tudela, el muy famoso y celebrado viajero judío, nacido en la famosa ciudad de la Ribera navarra hacia 1130, pocos años después de la conquista cristiana por Alfonso I el Batallador (1118). Hijo del rabino Yonah, solo sabemos de este personaje lo poco que de él se menciona en su famoso Libro de Viajes o Séfer-masa'ot, fruto de sus vivas experiencias -las más de las veces directas- exquisitamente plasmadas en su relación de viaje, que redactó en ágil y claro hebreo medieval. A finales de 1165 o principios de 1166 inicia su viaje desde Tudela y pasa por Zaragoza, Tortosa, Tarragona, Barcelona, Gerona, Narbona y otras localidades del sur de Francia para, desde Marsella y alternando vía marítima y terrestre, visitar Italia, Grecia, Constantinopla, Jerusalén, Bagdad, Damasco y Egipto, entre otros lugares, para regresar, hacia 1170, desde Sicilia a tierras de Castilla, como se dice en el prólogo de su relato.

Este libro de viajes se difundiría rápidamente entre los ambientes intelectuales del judaísmo europeo y oriental mediante copias manuscritas, a las que se añadieron, sin duda, otros materiales ajenos al cálamo y mano de Benjamín (como el prólogo anónimo y otras interpolaciones de corte fantástico y apologético), ampliando la extensión del texto básico redactado por nuestro viajero. El mejor y más completo manuscrito es el germánico custodiado en el British Museum, n..$^{\circ} 27.089$, pues transcribe con gran fidelidad y pureza los topónimos y antropónimos y 
otras voces no hebreas -latinas, griegas, árabes y romances- intentando imitar la pronunciación de la época. Algunos errores son meramente gráficos y debidos a descuidos del copista-escriba. Redactado a finales del siglo XII o principios del XIII, su relativa proximidad cronológica con las aventuras reales de nuestro viajero permite conjeturar una mayor pureza textual.

Tal sería la fama y difusión de los relatos de Benjamín que ya aparece la primera edición impresa del Séfer Masa'ot en 1543 a cargo del editor Soncino, en Istanbul. Fue esta una edición descuidada y precipitada, sin que sepamos en qué manuscrito se fundamenta. Contiene numerosos errores, que se fueron perpetuando y transmitiendo posteriormente ya que sirvió de base a las posteriores y primeras traducciones al latín y a otras lenguas europeas. Se conserva un solo ejemplar de esta editio princeps, incompleto, en la Bodleian Library de Oxford. Y mientras no aparezca otra edición que la supere, la que con toda justicia podemos calificar como mejor y más cuidada es la de Adler (1907) que se fundamenta en el antes citado códice n. ${ }^{\circ} 27.089$ del British Museum, ofreciendo un aparato crítico con las variantes de los otros manuscritos conocidos, así como copiosas notas aclaratorias a la pulcra traducción inglesa.

Benjamín inicia su periplo desde su Tudela natal, pasando por Aragón y Cataluña (aquí aporta escasas aunque interesantes noticias sobre sus correligionarios de Tarragona, Barcelona y Gerona del siglo XII), la Provenza francesa, los puertos de Marsella y Génova, Roma, Salerno, se interna en territorio del Imperio bizantino y ofrece una magna descripción de la fastuosa Constantinopla; pasa por Siria y la Palestina de los cruzados, visita los Santos Lugares de Jerusalén, Belén y Nablus, se traslada a Damasco, Alepo, Racca y Mosul, y por el valle del Tigris llega a la capital califal, Bagdad. Allí debió de residir largo tiempo, al amparo sin duda de la opulenta aljama judía, que con todo lujo de detalles describe. Bagdad sería su centro de operaciones y viajes menores por el área, quizás hasta el puerto de Basora, en la Baja Mesopotamia.

El texto hebreo continúa con diversas y exageradas descripciones de países, ciudades y ruinas de venerables sinagogas y sepulcros, vinculados a famosos personajes bíblicos y talmúdicos y antiguas tradiciones judaicas del ámbito mesopotámico, de Elam y de Persia. Sigue una serie de fantásticos viajes -acaso nunca realizados y obra de posteriores compiladores y redactores de los manuscritos- por lejanas latitudes de 
la India y la China -de las que más adelante trataremos-, si bien el relato se vuelve más realista y verosímil al tratar de Egipto: El Cairo, la vieja Fustat, Alejandría, el Monte Sinaí y Damietta, desde donde embarcó hacia Sicilia; desde esta isla, según se relata en el texto manuscrito, Benjamín va a Roma por segunda vez y, pasando por Lucca y Verdún, llegaría a París, donde bruscamente se termina el relato. Con todo, esta parte final del texto hebreo -que se refleja en todos los manuscritosparece que no es de la propia mano de Benjamín, sino que sería producto de la fértil y truculenta imaginación de algún compilador-redactor asquenacita. Esta interpolación incluye una idílica descripción de las comunidades judías del valle de Rhin, con referencias poco fiables a Bohemia, Esclavonia y Kíev, en la Rus primitiva. Esta ambientación centroeuropea no coincide con el tono mediterráneo y oriental del resto del Séfer-masa'ot. Lo más verosímil es que, como ya hemos mencionado antes, desde Sicilia se dirigiese directamente hacia poniente, recalando en Mallorca y desde algún puerto valenciano o catalán ultimase su definitivo viaje de regreso hasta llegar sano y salvo a su Tudela natal, hacia el año 1170.

Pero sería durante su prolongada estancia en la cosmopolita capital califal, Bagdad, y tal vez también en la portuaria Basora, cuando Benjamín, entre curioso, extasiado y maravillado, debió de escuchar de boca de mercaderes, aventureros y marinos -tanto judíos como musulmanes, para él veraces y fidedignos informantes, tal como consta en el prólogo introductorio al Libro de viajes, redactado en tercera persona por el anónimo compilador- toda una variada serie de sugestivos relatos, fantásticos e imaginarios hechos y sucesos, convenientemente mezclados y combinados con otras historias más o menos ciertas y reales, sazonadas con otras informaciones geográficas, etnográficas, religiosas y económicas sobre lejanos países y remotos lugares, ciudades, gentes y fenómenos naturales, de los que tomaría buena nota Benjamín, para posteriormente integrar todos esos materiales literarios en el cuerpo manuscrito de su Séfer-masa'ot, que sin duda debieron causar pasmo y asombro entre sus correligionarios tudelanos, pues eran "cosas que no habían sido oídas en tierras de Sefarad" (Magdalena Nom de Déu, 2002b: 16).

Entre los variados y maravillosos materiales geográficos, folclóricos, históricos y literarios procedentes de diversas tradiciones orientales que se incluyen en el Séfer-masa 'ot, el judío tudelano aporta algunas 
veladas y poco precisas informaciones -sin duda de segunda mano-, sobre la ciudad de Samarcanda y las ciudades de Tíbet, importante nodo de comunicaciones de la Ruta de la Seda

Sanyar Sah... que reina sobre el reino de Persia... es el rey desde la desembocadura del río Samara hasta la ciudad de Samarcanda; hasta el río Gozán y las ciudades de Tíbet, donde allí se encuentran, en sus bosques, los animales de donde se extrae el almizcle (Magdalena Nom de Déu, 2002b: 61).

Más adelante se amplían estas informaciones con datos más o menos complementarios:

Desde allí [desde Shiraz, en Persia] hay siete jornadas hasta Gaznah, la gran ciudad que está sobre el río Gozán... es un lugar de comercio y a ella vienen con mercadería [gentes] de toda lengua. Es un territorio muy extenso. Desde allí hay cinco jornadas hasta Samarkot; es la gran ciudad situada en el confín de la tierra de Persia... desde allí hay cuatro jornadas hasta Tíbet, país donde allí se encuentra mirra en sus bosques (Magdalena Nom de Déu, 2002b: 65).

También se hace mención del mar de India [en realidad es el golfo Pérsico] donde desemboca el río Tigris:

hacia una isla llamada Qis ${ }^{1} \ldots$ los comerciantes que vienen del país de India, de las islas, allí fondean con sus mercaderías; los del país de Sin'ar, el Yemen y el país de Persia traen allí ropajes de seda, púrpura, lino; y flor de crisantemo, algodón, y trigo, cebada, panizo, centeno y toda clase de comestibles y leguminosas, haciendo comercio unos con otros, pues los hombres de India importan aquí muchísimas especias y los isleños hacen el oficio de corredores entre ellos: de tal cosa viven (Magdalena Nom de Déu, 2002b: 69).

A unas diez jornadas de allí, por vía marítima, está el puerto árabe de Al-Qatif, donde se crían y pescan las ostras perleras, procesos y procedimientos que se describen adornados con curiosos y peregrinos

\footnotetext{
${ }^{1}$ Qesm, frente a la actual Bandar-Abbas, en el estrecho de Ormuz.
} 
detalles. Ya en el océano Índico², a siete jornadas náuticas, sitúa el puerto de Qulam, que es el puerto de Quilón, Cochí o Cochín, al sur de Calcuta, en la costa india de Malabar:

... que es comienzo del reino de los adoradores de sol; son los hijos de Kus y hacen predicciones en las estrellas. Todos son negros y honestos en sus negociaciones... allí se encuentra la pimienta... la caña azucarera, jengibre y muchas clases de especias... en toda la isla hay como un millar de israelitas entre todas las ciudades; todos los señores de este país son negros, asimismo los judíos son negros: son buenos judíos, observantes de los preceptos (Magdalena Nom de Déu, 2002b: 70).

A veintitrés jornadas náuticas de este puerto malabar sitúa el texto de Benjamín la isla de Labrig, Ibrig o Ceilán, también conocida hoy como Sri-Lanka, que a lo largo de su milenaria y rica historia ha llevado asimismo, entre otros, los nombres de Selan, Lanka, Lankadvīpa, Simoundou, Taprobane y Serendib. Cifra harto exagerada, sin duda, pues las exageraciones e imprecisiones metrológicas aparecen como recurso frecuente en muchos relatos de viajes medievales. Sin embargo, en el género travelogue

It is clear that ... incorporating and describing quantitative data in the texts was enormously important. Above all, the insertion of very different measurements and distances gives the story an unquestionable testimonial value, adding further veracity to the description (Mironesko Bielova, 2016: 431).

En aquella ínsula habitan "los adoradores del fuego" o dokhbin, cuyos "sacerdotes son grandes brujos en toda clase de hechicería" (Magdalena Nom de Déu, 2002b: 71); mediante sofisticados engaños y encantamientos diversos consiguen que los crédulos fieles hagan voto de suicidarse arrojándose a las llamas, previo reparto de sus bienes y pago de deudas atrasadas.

Y a partir de aquellos lejanos parajes de las costas meridionales de la India y Ceilán, el texto hebreo de Benjamín -conteniendo muchos más errores y fantasías que aciertos y realidades- indica que "desde allí al

\footnotetext{
${ }^{2}$ Interesa el libro de Zethaoui, Monique. 2000. Shalom India. Histoire des communautés juives en Inde. Paris; especialmente el capítulo II Le Moyen Àge. Le récit de Benjamin de Tudèle.
} 
otro lado de la tierra de China [Șywn] hay una distancia de cuarenta jornadas: es el Extremo Oriente" (Magdalena Nom de Déu, 2002b: 72). Los manuscritos ofrecen este topónimo muy deturpado: en el ms. n. ${ }^{\circ} 27.089$ del British Museum, siglos XII-XIII: וןיצ' "[Șywn]” y en el n. ${ }^{\circ} 26$ Casanatense (Roma, siglo XV): "ןיצ-לא "al-Șyn”. El nombre China, atribuido al lejano y fabuloso país oriental, empezó a correr por Europa mediante la difusión de los relatos de Marco Polo (traducidos al latín y a varias lenguas locales a partir de principios del siglo XIV) y deriva de la voz persa "cin", que antiguamente designaba cierta porcelana procedente de aquellas latitudes; está emparentada con la voz sánscrita "cīnā", cuya primera documentación es el Mahābhārata (siglo IV a. C.) y posiblemente se refiera al topónimo Qin (秦), la estructura político-cultural más occidental de los antiguos reinos chinos (778 a. C. - 207 a. C.). Otras denominaciones medievales, ya más tardías, que circularon entre los europeos fueron "Sina" y "Catay".

Sigue el relato con informaciones indirectas acerca del océano glacial o mar "helado" (la voz hebrea אפקנ de los manuscritos se puede asimismo interpretar y traducir como "congelado", "espesado", "opaco", "cuajado", "condensado", "coagulado", "inmóvil", “yerto", "rígido") donde soplan fuertes y peligrosos vientos que desvían el rumbo de las naves, empujándolas hacia la perdición.

Como advierte Malcolm Letts "It must be remembered that no medieval travel book was complete without some account of strange human beings and marvellous creatures" (Letts, 1946: XVI). El relato de Benjamín de Tudela sigue esta tradición del travelogue medieval. Así, resulta harto curiosa e interesante la información que incluye el viajero judío sobre un ave imaginaria cuyo origen se remonta a tiempos remotísimos. El mítico grifo del texto hebreo (en el ms. 27.089 de British Museum, siglos XII-XIII): ופירג "grypw" = grifo, y en el n. "26 Casanatense (Roma, siglo XV):ינופריג:" "gyrypwney” = grifone), al igual que otras fantásticas criaturas, parece que resucita en la época medieval a la vez que cobra gran protagonismo y adquiere nuevas interpretaciones a lo largo y ancho de todo el panorama medieval (Bestiario medieval, 1999: 138143; Magdalena Mironesko \& Mironesko Bielova, 2015: 37-38, 57).

Según el sabio arabista Juan Vernet, el grifo o rujj descrito en el texto hebreo de Benjamín constituye el último eco del Aepyornis maximus, ave corredora semejante al avestruz gigante de Madagascar, extinta en el siglo XVIII (Vernet, 1953a: 102-105) 
hay quienes dicen que allí el mar está helado; en dicho mar domina la estrella de Orión ${ }^{3}$. A veces sopla allí un viento tormentoso y ningún marino puede gobernar la nave debido al ímpetu del viento, que finalmente arroja la nave en el mencionado mar helado y no puede moverse de su sitio; sus tripulantes resisten hasta el fin de sus vituallas y después mueren; algunas naves se pierden de este modo. Pero algunas personas han aprendido un ardid para escaparse de ese mal lugar: toman pellejos de grandes reses y si les viene dicho viento y los arroja hacia el mar helado, uno toma el pellejo y se introduce en su interior provisto de un cuchillo en la mano, cose el pellejo para que no entre agua en él y se arroja él mismo en medio del mar helado. Lo ve la gran águila llamada grifo y, suponiendo que es una bestia, la saca hacia tierra firme posándose con ella misma en un monte o valle para comerla. El hombre se apresura y la hiere con el cuchillo, matándola, sale del pellejo y camina hasta que llega a lugar poblado. De esa manera se han salvado muchos hombres (Magdalena Nom de Déu, 2002b: 72-73).

También Dubler ofrece el interesante texto árabe del viajero andalusí de finales del siglo XII -coetáneo, pues, de Benjamín de TudelaAbu-Hamid al-Garnati, y su traducción castellana:

... hay una especie de pájaros grandes, con picos muy largos. Los picos de estos pájaros están vueltos a la derecha y a la izquierda; la parte de arriba, seis palmos a la derecha y seis palmos a la izquierda... sólo cuando comen y beben cierran el pico, para poder hacerlo. La carne de este pájaro es buena para los que padecen de cálculos de riñón y vejiga, y se la lleva a Bulgar en lonchas secadas al sol, que hay que despedazar. Si el huevo de este pájaro cae sobre hielo o nieve, se funde como por el fuego. No se conserva más que sobre tierra o madera (Dubler, 1953: 60-61).

Y más adelante, Dubler añade el erudito comentario:

... nuestro autor [Abu-Hamid al-Garnati] alude en otro lugar al mismo pájaro que posee un pico... con virtudes peculiares; esta ave debe ponerse en parangón con el rujj, -ave que también se relaciona con el

\footnotetext{
${ }^{3}$ Escribe Juan Vernet: “La estrella que aquí se llama indebidamente Orión es Cánope", también conocida como Canopus o Canopo. "Orión es la constelación o conjunto de estrellas que llaman El Cazador, bien visible desde ambos hemisferios terrestres" (1953b: 8-9).
} 
rejuvenecimiento del hombre- del mar de la China, del que habla por primera vez Abu Hamid y que ingresó en el gran cuerpo de los relatos de las "Mil y una noches". Aun hoy día, los habitantes de esas comarcas septentrionales conservan viva la creencia en un pájaro fabuloso, caracterizado por su enorme pico. (Dubler, 1953: 308-309).

Estas variopintas, fantásticas y caóticas informaciones sobre el extremo Oriente las debió escuchar el viajero tudelano en la cosmopolita Bagdad o en el puerto de Basora, de boca de correligionarios por él considerados "veraces" y fidedignos, cuidadosamente anotadas en su cuaderno y posteriormente incorporadas al cuerpo del relato. Pero Benjamín de Tudela no llegó tan lejos, ni pudo ser testigo directo de cuanto se contiene en su relato. Ya a principios del siglo pasado, Ignacio Agustín González Llubera observa que:

limitándonos a la obra tal como ha llegado a nuestro tiempo, es notable la diferencia que se observa en el relato a partir de Bagdad: hay frases que manifiestan que habla de oídas [...] se inserta un episodio completamente fabuloso -el del grifo-, y las descripciones de costumbres de la India, de Catifa, de Abisinia, etc., tienen un carácter muy ajeno al de Benjamín, que tiende siempre a concretar los hechos. Al llegar a Egipto, reaparecen todas aquellas cualidades que comunican al lector la sensación de la realidad. La consecuencia que la crítica deduce, es que Benjamín no llegó más allá de Bagdad y sus alrededores, pasando luego a Egipto (González Llubera, 1918: 29-30).

Años más tarde, en 1962, el arabista Juan Vernet en un documentado artículo donde pasa pormenorizado análisis y revista a los aspectos geográficos y folclóricos del itinerario de nuestro viajero, al comentar los pasajes dedicados al lejano Oriente -la China, el mar Helado, el grifo, etc.- puntualiza:

Tras la descripción sumaria de unos cuantos puertos encontramos a Benjamín de Tudela, de nuevo realmente y en persona, en Adén. Desde aquí la descripción de caminos se hace más precisa... (Vernet, 1962: 210).

Benjamín de Tudela no llegó, pues, a tan remotos parajes y latitudes ni visitó la India ni la China. Todas las fantásticas, inexactas y caóticas informaciones y noticias que se contienen en el texto hebreo de su relato 
acerca del Lejano Oriente (Samarcanda, Tíbet, costa índica de Malabar, Ceilán, la China...) así como otros datos sobre territorios del Yemen y África oriental, el crédulo judío tudelano los oiría contar a informantes judíos y musulmanes del ámbito arabófono oriental, anotándolas como ciertas y fidedignas en su diario, para ser encontradas correctas, exactas e irrefutables entre sus correligionarios a su regreso a tierras de Sefarad, como se hace constar en el prólogo.

¿Mintió, pues, Benjamín de Tudela? ¿o acaso exageró el anónimo prologuista-redactor que dio forma y estructura literaria al relato final que después circularía como libro de viajes entre las comunidades judías europeas y orientales? Sea como fuere, creemos que las fantasías, interpolaciones y pasajes dudosos que sobre el Lejano Oriente y otras regiones asiáticas y africanas contiene el texto hebreo del viajero judío tudelano de la segunda mitad del siglo XII no son sino unos recursos y estereotipos estilísticos al uso, muy frecuentes en este fabuloso género literario. Imaginarios y recurrencias como los que, por ejemplo, detecta y comenta Malcolm Letts en la introducción al relato del peregrinaje del caballero alemán Arnold von Harff por Europa, África, Tierra Santa, Arabia y países asiáticos (noviembre de 1496 a octubre de 1999):

It is clear to me that von Harff did not visit India, Madagascar, or Central Africa, still less did climb the Mountains of the Moon or discover the source of the Nile. I think that von Harff may have visited the island of Socotora -if not he must have obtained very accurate information at Aden- and as to the Arabian episode I am disposed to give him the benefit of the doubt. It is possible that when he sat down to compile his narrative he was plagued with questions about the East, the Garden of Eden, the situation of Paradise, the source of the Nile, the country of Prester John, and the strange beings and creatures to be found there, and he could not bring himself to disappoint his public... (Letts, 1946: $\mathrm{XVI})$.

Moviéndonos, pues, en el resbaladizo terreno de las conjeturas, pareciera razonablemente posible -y acaso bastante probable- que a tales recursos y estereotipos estilísticos debió recurrir nuestro viajero tudelano, añadiendo fantasía y exotismo a sus notas, sin malicia mendaz y solamente con ánimo de ampliar y hermosear sus aventuras y relatos, para deleite y pasmo de sus lectores; o bien fue posterior refacción literaria de los copistas que después dieron forma más o menos definitiva 
al textus receptus del Séfer masa'ot, tal como circuló y nos ha llegado en sus variantes manuscritas.

\section{Bibliografía}

Adler, Mordekay Natan. 1907. The Itinerary of Benjamin of Tudela. Critical, text, Translation and Commentary. London: Oxford University Press.

Adler, Elkan. 1930. Jewish Travellers in the Middle Ages. London: G. Routledge \& Sons, Ltd.

Arias Montano, Benito. 1575. Itinerarium Beniamini Tudelensis in quo res memorabiles, quas ante quadringentos annos totum fere terrarum orbem notatis itineribus dimensis vel ipse vide vel a fide dignis suae aetatis hominibus accepit, breviter atque dilucide describuntur; ex hebraico latinum factum Bened. Arias Montano interprete. Amberes: Christophorus Plantinus.

Bestiario medieval. Edición y traducción del inglés de Ignacio Malaxecheverría. 1999. Madrid: Ediciones Siruela.

Díaz Esteban, Fernando. 2009. Las noticias sobre China en los libros hispanoportugueses de los siglos XVI y XVII. Boletín de la Real Academia de la Historia CCVI-I: 37-64.

Dubler, César Emilio. 1953. Abu Hamid el Granadino y su relación de viaje por tierras eurasiáticas. Madrid: Imprenta y Editorial Maestre.

Freedman, Marci. 2016. The Transmission and Reception of Benjamin of Tudela's Book of Travels from the Twelth Century to 1633 (Tesis Doctoral). University of Manchester.

Gil, Moshe. 1976. The Radhanite Merchants and the Land of Radhan. Journal of the Economic and Social History of the Orient 17: 299-328.

González Llubera, Ignacio Agustín. 1918. Viajes de Benjamín de Tudela. 11601173. Por primera vez traducidos al castellano con introducción, aparato crítico y anotaciones. Madrid: Sanz Calleja Editores e Impresores.

Israeli, Raphael. 2000. Medieval Muslim Travelers to China. Journal of Muslim Minority Affairs 20(2): 313-321.

Letts, Malcolm. 1946. The Pilgrimage of Arnold Von Harff Knight from Cologne, through Italy, Syria, Egypt, Arabia, Ethiopia, Nubia, Palestine, Turkey, France and Spain, which he accomplished in the years 1496 to 1499. Translated from the German and edited with notes and an introduction by-. London: Hakluyt Society.

Magdalena Nom de Déu, José Ramón. 1982a. Libro de viajes de Benjamín de Tudela. Versión castellana, introducción y notas. Barcelona: Riopiedras Ediciones. 
Magdalena Nom de Déu, José Ramón. 2002b. Benjamín de Tudela. Libro de Viajes. Pamplona: Ediciones y Libros S. A.

Magdalena Mironesko, Alexandra \& Mironesko Bielova, Elena. 2015. Физиолог en la literatura rusa medieval. Aproximación a un análisis descriptivo-comparativo. Barcelona: Trialba.

Mironesko Bielova, Elena. 2016. The phrasebook ['razgovornik'] as a communication tool for medieval Russian travelers. Postmedieval: a Journal of medieval cultural Studies 8(4): 425-443.

Raiskin, Shlomy. 2006. A Bibliography on Chinese Jewry. Moreshet Israel. Journal of Judaism, Zionism and Eretz-Israel 3: 60-85.

Rodríguez Ochoa, José María. 2015. Vida y obra de Benjamín de Tudela: El libro de viajes/Bidaien liburua. Sefer massa'ot. Personajes navarros 9, Pamplona: Gobierno de Navarra. Fondo de Publicaciones.

Sáenz-López Pérez, Sandra. 2010. El vuelo de Oriente a Occidente del mítico pájaro Rujj y las transformaciones de su leyenda. Anales de Historia del Arte, volumen extraordinario: 327-344.

Vernet, Juan. 1953a. RUJJ = Aepyornis maximus. Tamuda I: 102-105.

Vernet, Juan. 1953b. Influencias musulmanas en el origen de la cartografía náutica. Boletín de la Real Sociedad Geográfica 99: 8-9.

Vernet, Juan. 1962. Benjamín de Tudela. Príncipe de Viana: 200-211.

Weil, Shalva. 2002. India's Jewish Heritage: Ritual, Art and Life-Cycle. Mumbai: Marg Publications.

Zethaoui, Monique. 2000. Shalom India. Histoire des communautés juives en Inde. Paris: Éditions Imago. 